A-rkivoc

Free to Authors and Readers
A Platinum Open Access Journal for Organic Chemistry
Paper

Arkivoc 2021, part vii, 128-140

\title{
Computational investigation of cyclic substituted iodine(III) halogen bond donors
}

\author{
Raphaël Robidas, ${ }^{\text {a }}$ Stefan M. Huber, ${ }^{\text {b* }}$ and Claude Y. Legault ${ }^{\text {a* }}$ \\ ${ }^{a}$ Department of Chemistry, Université de Sherbrooke, Sherbrooke, Canada \\ ${ }^{b}$ Department of Chemistry and Biochemistry, Ruhr-Universität Bochum, Bochum, Germany \\ Email: claude.legault@usherbrooke.ca, stefan.m.huber@rub.de
}

Received 09-09-2021

Accepted Manuscript 10-16-2021

Published on line 11-12-2021

\section{Abstract}

Several novel substituted iodine(III)-based halogen bond donors have been computationally investigated using density functional theory (DFT). Their properties of interest related to their Lewis acidity and stability were evaluated. These results constitute a theorical background for the rational design of new active iodine(III)-based organocatalysts. Notably, cyclic diaryliodonium salts with a central six-membered ring (iodininium salts) have been identified as a promising new class of halogen bond donors, although highly Lewis acidic variants have not been synthetized yet.

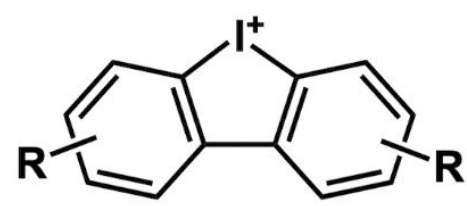<smiles>[R][X]1=C=Cc2c(ccc([Y])c2[Y])[I+]1</smiles>

\section{Computational Analysis}

\section{Effect of $R$ on probable degradation pathways Optimization of stability vs Lewis acidity}

Keywords: Hypervalent iodine, Iodolium ions, Diaryliodonium ions, Halogen bonding, Lewis acids, Computational chemistry 


\section{Introduction}

lodine(III) compounds have emerged as powerful halogen bond donors. ${ }^{1}$ Most of these compounds are diaryliodonium salts, either cyclic or acyclic. The aryl moieties can be functionalized to optimize the properties of these halogen bond donors for specific applications. The variations in Lewis acidity have been quantified previously by both of our groups for diversified sets of compounds. In particular, the Lewis acidity of a small set of acyclic diaryliodonium salts has been first determined by NMR using the Gutmann-Beckett method, ${ }^{2}$ then, using different titration methods, an extended set of iodine(III) compounds was investigated. ${ }^{3}$ Cyclic diaryliodonium salts have been mostly studied using isothermal calorimetry (ITC) ${ }^{4-6}$ as well as by ${ }^{1} \mathrm{H}$ NMR titrations. ${ }^{5}$ In particular, cyclic diaryliodonium salts have been shown to possess Lewis acidities that can rival those of dicationic bidentate iodine(I) halogen bond donors. ${ }^{4}$

Diaryliodonium salts have consequently been used as organocatalysts for a three component Mannich reaction, ${ }^{7}$ the Ritter-type solvolysis of benzyl halides and benzhydryl halides, ${ }^{4,6,8}$ a Diels-Alder reaction, ${ }^{4,9}$ the activation of a metal-halogen bond, ${ }^{10}$ Michael and nitro-Michael additions ${ }^{9}$ and Knorr-type reactions. ${ }^{11}$ Of course, the activity of the catalysts is highly dependent on their Lewis acidity. In order to obtain the most active catalysts possible, substituents can be introduced to modulate their properties. However, the stability of the catalyst must also be kept in mind, as iodine(III) compounds could be prone to reduction into their more stable iodine(I) form. This is the common and desired behaviour when they are involved in iodine(III)-mediated oxidative methodologies, but this behaviour must be tamed when using them as organocatalysts. Substituents must thus be carefully chosen to maximize the Lewis acidity while preserving the stability of the catalyst. The molecular scaffold of the iodine(III) compound also has a significant influence on those two properties, as exemplified by the stark difference between diphenyliodonium triflate and dibenzo[ $[b, d]$ iodolium triflate. ${ }^{3}$ Indeed, cyclic iodolium triflate has been shown to be nearly two orders of magnitude more Lewis acidic than the corresponding acyclic compound. The Lewis acidity could further be increased with electron-withdrawing groups, although limited substituents were screened for the cyclic halogen bond donors.

In the mindset of further exploring more diverse structures, one of our groups has studied the properties of cyclic six-membered diaryliodonium salts (also called iodininium salts, Figure 1). ${ }^{6}$ They were shown to be active Lewis acids in the Ritter-type solvolysis of $\alpha$-methyl-benzyl bromide, although the group linking the two aryl moieties had an important influence on their activity. This mandated further investigation into the properties of this new class of halogen bond donors. However, the synthesis of many such compounds is of course not trivial nor practical. We thus envisioned using computational chemistry to screen many possible linkers and substituents to identify promising candidates.

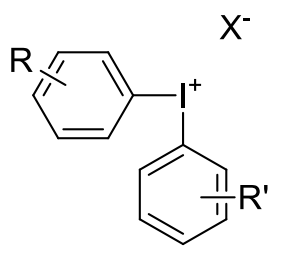

Acyclic diaryliodonium salts

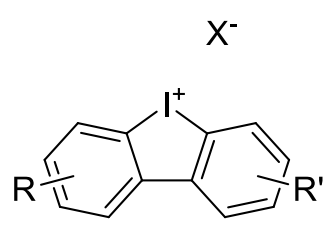

lodolium salts

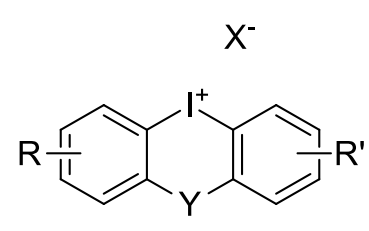

lodininium salts

Figure 1. Classes of iodine(III) halogen bond donors. 
We chose to study both the Lewis acidity of a wide range of $X B$ donors as well as two plausible decomposition pathways, namely reductive elimination (RE) and single electron transfer (SET). Like the acyclic diaryliodonium salts, the cyclic variants can undergo reductive elimination with an external nucleophile (Scheme 1). This pathway is however considered less probable in iodolium salts due to the important geometrical distortion involved in this process. We wanted to quantify the barrier of this process for iodolium and iodininium salts in order to predict their relative stability towards (anionic) nucleophiles. Similarly, we expect the reduction of diaryliodonium salts by SET to be a significant probable decomposition pathway. The propensity of reduction through this pathway can be assessed by calculating the vertical electron affinity (VEA). ${ }^{12}$ The adiabatic electron affinity is unsuitable in this case, as the iodine(II) radical shifts to its aryl radical form with essentially no barrier.

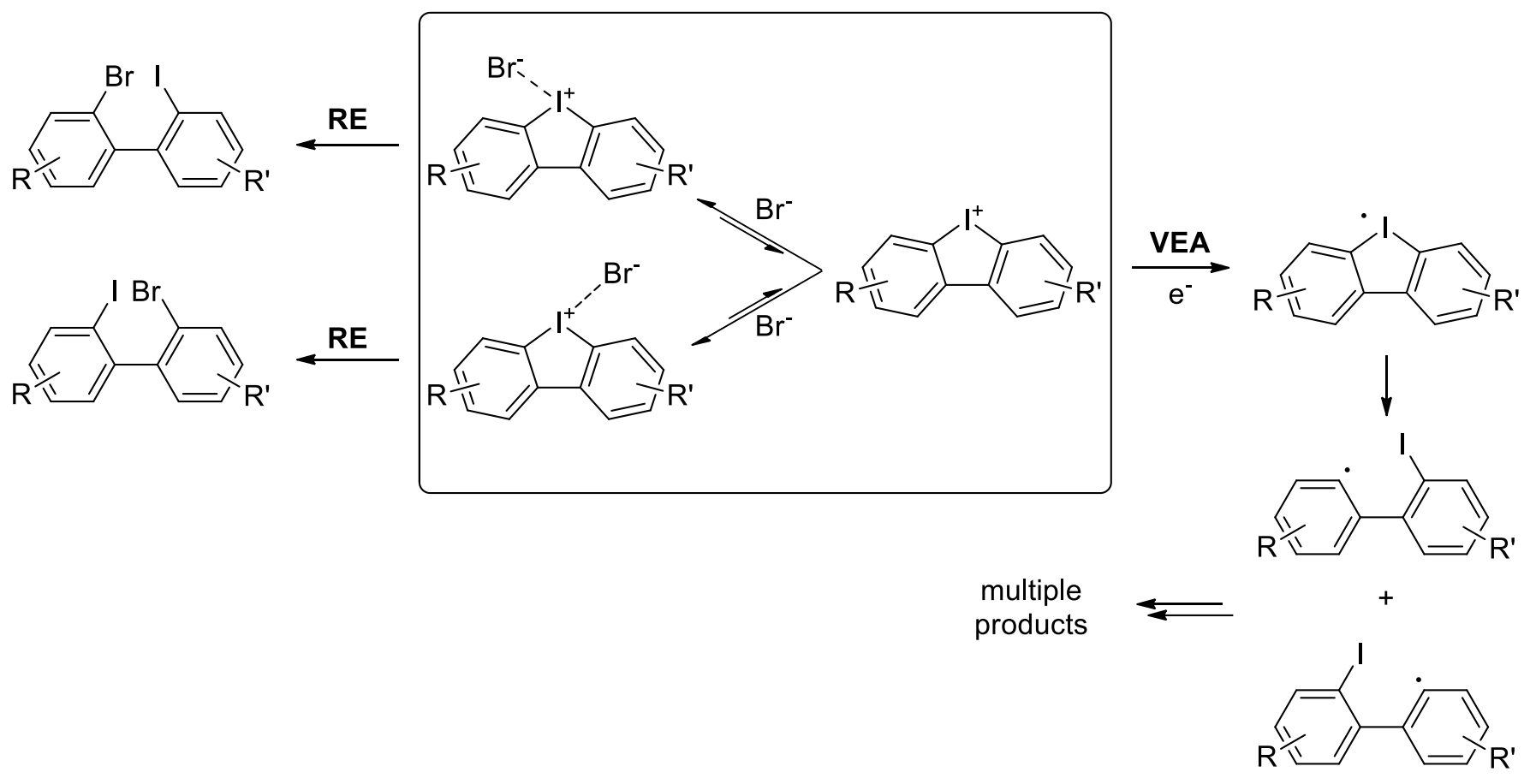

Scheme 1. Modeled equilibria and decomposition pathways of iodolium cations with bromide as a prototypical Lewis base and nucleophile.

\section{Results and Discussion}

We modeled a range of mono- and symmetrically disubstituted iodolium cations (Figure 2). Five different functional groups ranging from very electron-donating to very electron-withdrawing were added in every case. To probe the Lewis acidity of these compounds, we used the bromide anion as Lewis base and calculated its complexation free energy to the iodolium cations. The relative calculated values were in good accordance with experimental values (see Supporting Material). The activation barriers to its reductive elimination were also calculated. In addition, the vertical electron affinities were computed based on the optimized structures of the iodolium cations. 
a)<smiles></smiles>

b)<smiles>[R]c1cccc2c1[I-]c1ccccc1-2</smiles><smiles>[R]c1ccc2c(c1)[I-]c1ccccc1-2</smiles><smiles>[R]c1ccc2c(c1)-c1ccccc1[I-]2</smiles>

$3_{R}$<smiles>[R]c1ccc2c(c1)-c1cc([R])ccc1[I+]2</smiles>

$6_{R}$<smiles>[R]c1ccc2c(c1)[I-]c1cc([R])ccc1-2</smiles>

$7_{R}$<smiles>[R]c1cccc2c1-c1ccccc1[I+]2</smiles>

$4_{R}$<smiles>[R]c1cccc2c1[I-]c1c([R])cccc1-2</smiles>

$8_{R}$

$\mathrm{R}=\mathrm{NMe}_{2}, \mathrm{OMe}, \mathrm{F}, \mathrm{CN}, \mathrm{CF}_{3}$

Figure 2. a) Numbering of the iodolium cation scaffold; b) Substitution patterns of the core.
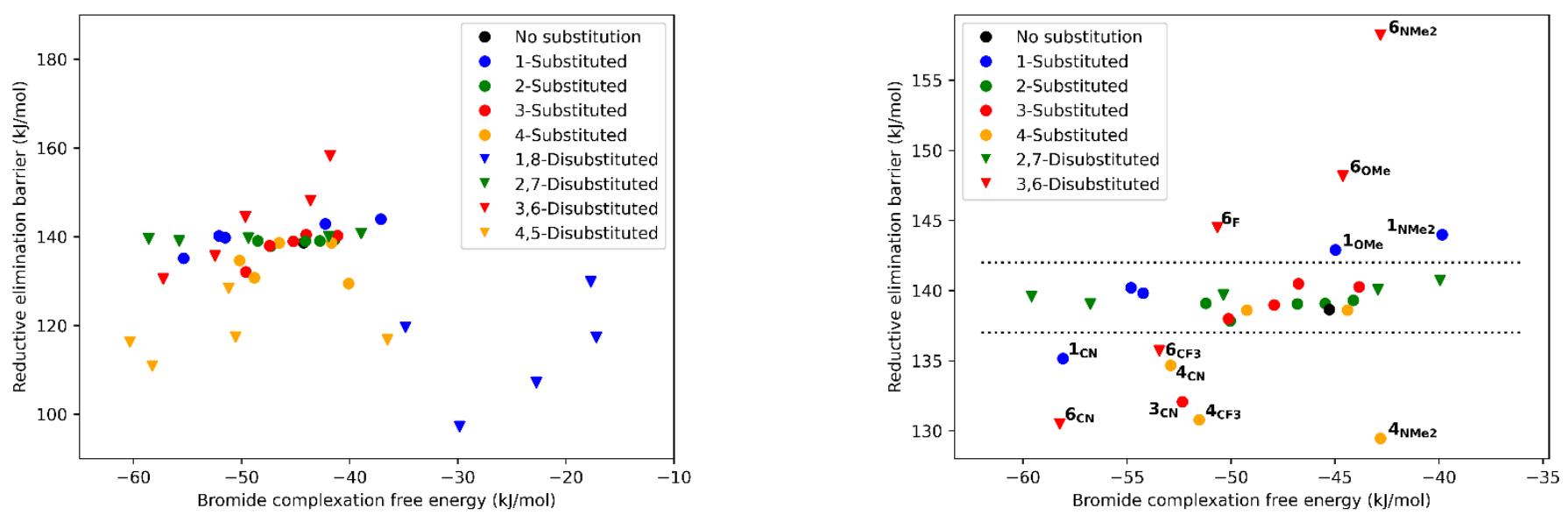

Figure 3. a) Relationship between the reductive elimination barrier and the Lewis acidity; b) Same relationship but excluding 1,8-disubstituted and 4,5-disubstitued compounds.

For every compound, the reductive elimination barrier was plotted against the bromide complexation free energy in Figure 3a. We observe a fairly limited deviation between the families, with the exception of the 1,8(8) and 4,5-disubstituted (5) families. Firstly, it is apparent that 1,8-disubstituted XB donors 8 are generally poor Lewis acids due to the important steric and electrostatic repulsion near the binding sites (see Figure $4 \mathrm{~b}$ for an example). This is coherent with the measured reduced Lewis acidity ${ }^{3}$ and their low activity as catalysts. ${ }^{4}$ Moreover, 4,5-disubstitued XB donors (5) are also more prone to reductive elimination. This is mostly due to the additional tension by the proximity of the two substituents (see Figure 4c). The 4,5-difluoroiodolium cation 
$\mathbf{5}_{\mathbf{F}}$ has the least strain of the 4,5-disubstitued compounds, although its reductive elimination barrier of 128 $\mathrm{kJ} / \mathrm{mol}$ remains lower than the average. We have thus removed the 1,8-disubstituted and 4,5-disubstitued compounds in the further analyses, as they appear unfit to be active and stable catalysts.

a)

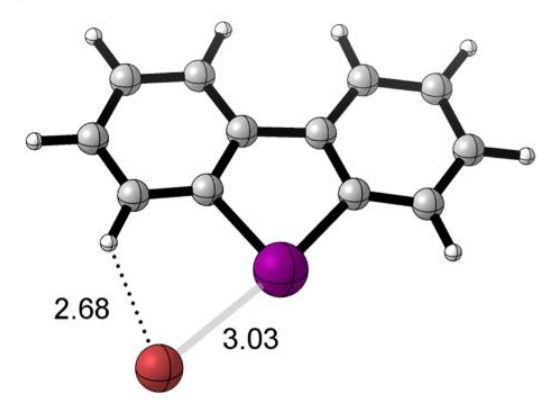

b)

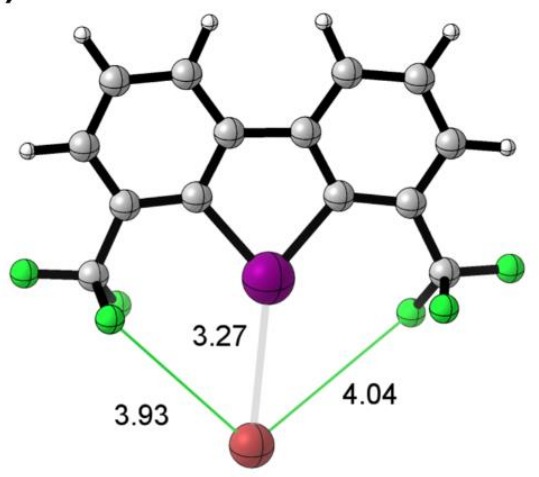

c)

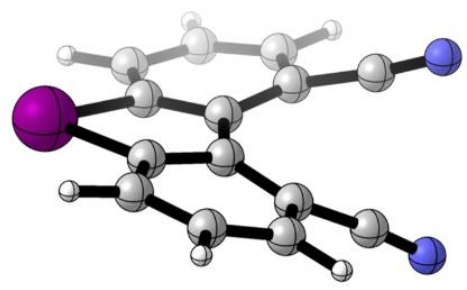

Figure 4. a) Binding of bromide to the unfunctionalized iodolium cation $\mathbf{1}_{\mathbf{H}}$; b) Binding of bromide to the sterically blocked 1,8-bis(trifluoromethyl)iodolium cation 8 cF3 c) Distortion of the 4,5-dicyanoiodolium cation $5 \mathrm{cN}$.

In the case of the other compounds, the reductive elimination barrier is, interestingly, only slightly influenced by substituents and most of the values are very close to $140 \mathrm{~kJ} / \mathrm{mol}$ (Figure $3 \mathrm{~b}$ ). This stems from the combination of two effects which cancel each other out: on one hand, substituents influence the free energy of the reductive elimination transition state with respect to the free iodolium cation and the bromide in solution, but the Lewis acidity is changed by nearly the same measure (See Figure 5). This results in an overall barrier (from adduct to transition state) that remains fairly constant, as illustrated in Figure 6. To be more exact, we see that the slope of the trendline in Figure 5 is 1.34, which indicates that the relationship is not direct. However, from this slope, we would expect a maximal variation in the reductive elimination barrier of around $8 \mathrm{~kJ} / \mathrm{mol}$ over the entire range of compounds, which is relatively small. From this data, it should be expected that any of these candidates would be kinetically stable toward reductive elimination at room temperature (or mild heating).

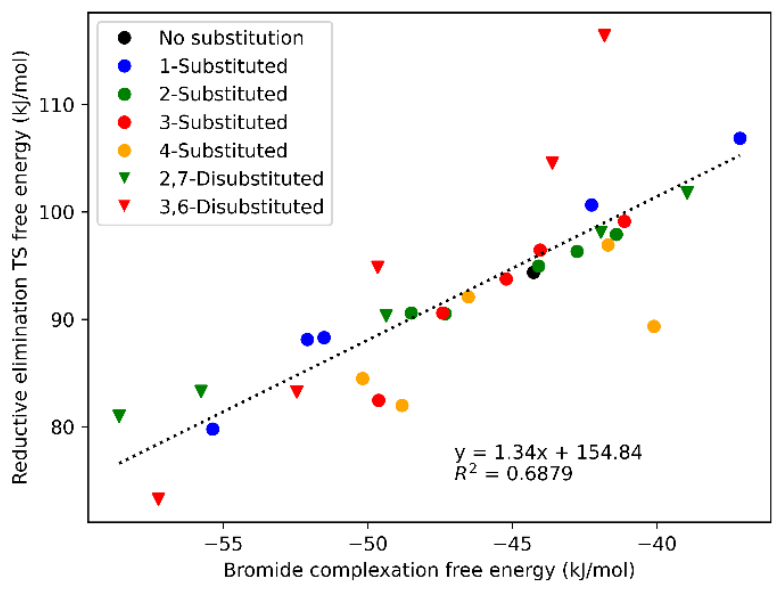

Figure 5. Variation of the reductive elimination transition state free energies relative to the dissociated ions. 


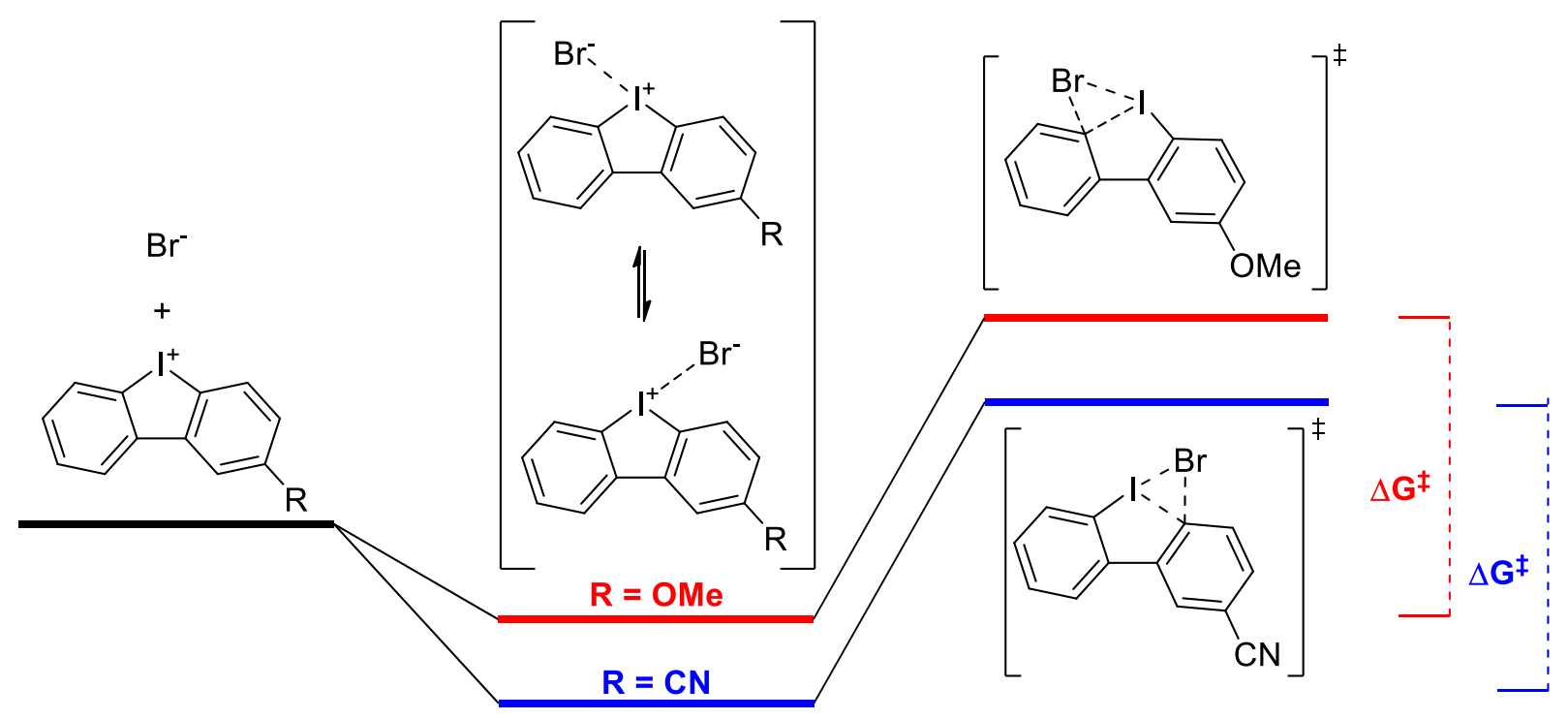

Figure 6. Illustration of the two opposite trends leading to nearly constant reductive elimination barriers.

The correlation between the vertical electron affinity and the bromide complexation free energy for the entire iodolium set is shown in Figure 7a. In this case, only the 1,8-disubstituted compounds deviate from the general trend. Interestingly, 1,8-bis(trifluoromethyl)iodolium $\mathbf{8}_{\text {cF3 }}$ appears to possess a low electron affinity, despite the strongly electron-withdrawing groups. This could be explained by additional repulsion between the multiple fluorine atoms and the additional electron density on the iodine atom. Indeed, the two closest fluorine atoms are at only $2.8 \AA$ of the iodine atom, which could destabilize the radical species.

If we omit the 1,8-disubstituted iodolium species, a good linear trend between the vertical electron affinity and the bromide complexation free energy is obtained (Figure 7b). This means that more active iodolium-based catalysts will be necessarily more prone to reduction by SET. However, there appears to be some factors which can allow deviation from the trend, as illustrated in Figure $7 \mathrm{~b}$.
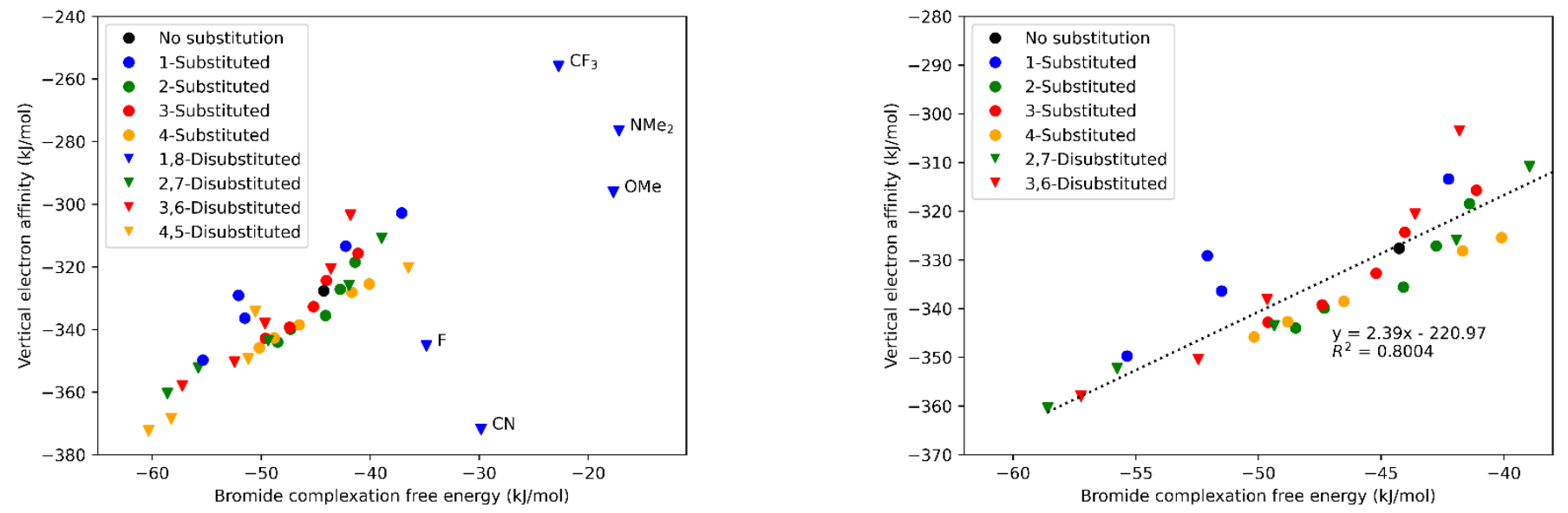

Figure 7. a) Variation of the vertical electron affinity of iodolium cations; b) Same trend, but without 1,8disubstituted and 4,5-disubstitued compounds. 
The issue of reduction by SET must however be nuanced: in the absence of suitable reducing agents, even highly active iodolium catalysts are stable, as shown by experiments. 1,2,3,4-Tetrafluoroiodolium 9 has been found to be a highly active, yet stable, XB donor in the context of a Ritter-type solvolysis benchmark reaction (Scheme 2). ${ }^{6}$ The calculations indicate a remarkable Lewis acidity (bromide complexation free energy of -66 $\mathrm{kJ} / \mathrm{mol}$ ) which surpasses that of all the other iodolium cations. As for the predicted stability, the reductive elimination barrier $(144 \mathrm{~kJ} / \mathrm{mol})$ is even higher than for the unsubstituted iodolium cation $\mathbf{1}_{\mathrm{H}}$. In contrast, the vertical electron affinity is extremely favorable $(-363 \mathrm{~kJ} / \mathrm{mol})$ compared to other iodolium cations. Nonetheless, the compound was found experimentally to be stable enough to be analyzed by X-ray diffraction and used in the model reaction described above. This demonstrates that even with an electron affinity this low, it could still be suitable for reactions such as Ritter-type solvolysis; their stability in other reaction conditions is however uncertain.

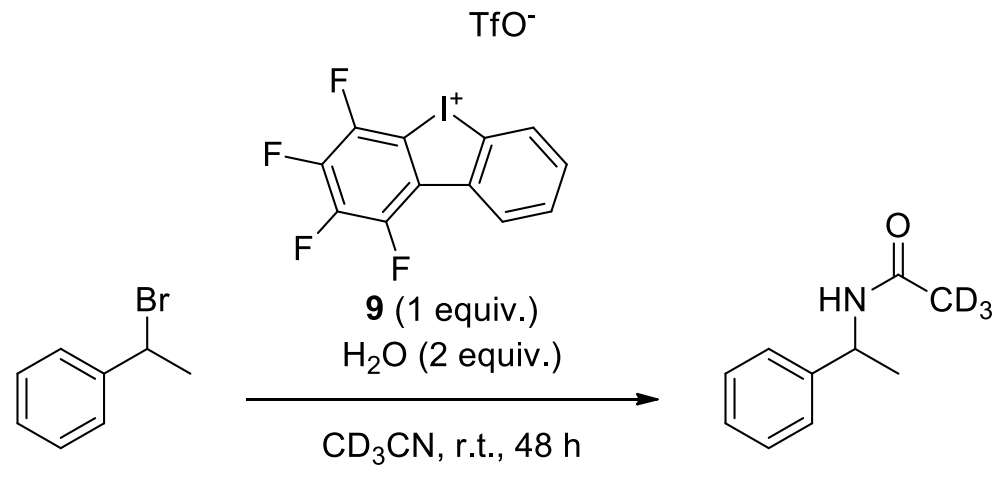

Scheme 2. Ritter-type solvolysis promoted by halogen bond donor 9 as triflate salt. ${ }^{6}$

The effect of each substituent can be further analyzed depending on its position, on mono-substituted systems $\left(\mathbf{1}_{\mathbf{R}}-\mathbf{4}_{\mathbf{R}}\right)$. The effect on the complexation free energies appears mostly constant, regardless of the position (Figure 8). We however note larger variations for substituents at the 1 position, ortho to the iodonium center. This likely comes from the increased interactions with the iodine atom, and with the bromide anion in the case of its complexation. For example, electron withdrawing groups such as the trifluoromethyl, cyano and the fluoro group both increase the bromide complexation energy more at the 1 position than elsewhere. While the trifluoromethyl group does block one binding site, the Lewis acidity of the other is increased. In contrast, the trifluoromethyl group actually does not significantly increase the vertical electron affinity when linked at the 1 position (Figure 8b). As stated earlier, this could be explained by electrostatic repulsion between the partially negative fluorine atoms and the additional electron density of the iodine atom. 

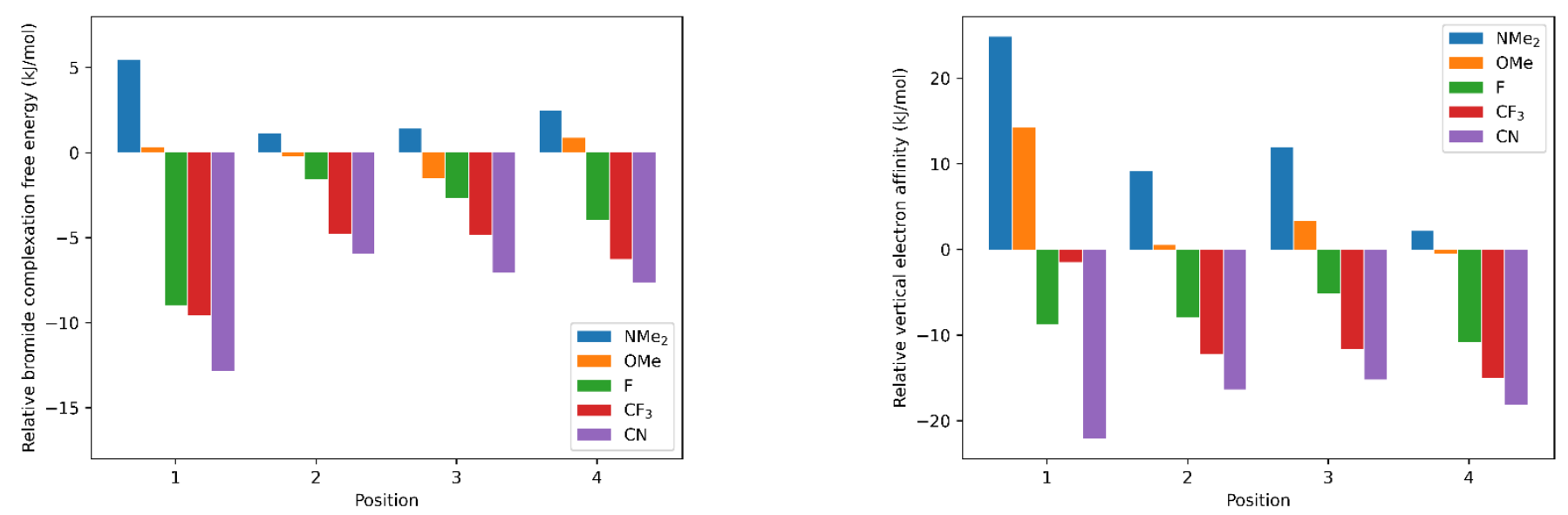

Figure 8. Relative properties compared to cation $\mathbf{1 H}$ depending on the substituent and its position on the iodolium scaffold; a) Bromide complexation free energy; b) Vertical electron affinity.

As mentioned earlier, cyclic diaryliodonium salts with a central six-membered ring, coined iodininium salts, have started to be investigated by one of our groups. ${ }^{6}$ Unfortunately, the two particular iodininium compounds that were synthetized in that work did not outperform 1,2,3,4-tetrafluoroiodolium 9. Yet, many more linking groups than the ones tested (methylene and oxygen) have been reported in the literature. We thus elected to evaluate computationally which ones could provide an increased Lewis acidity, while remaining stable enough to be useful catalysts (Figure 9). Indeed, many variations could be highly Lewis acidic, yet be highly prone to SET reduction or reductive elimination with a nucleophile.<smiles>O=S1c2ccccc2[I-]c2ccccc21</smiles>

$10_{\text {so }}$<smiles>O=S1(=O)c2ccccc2[I+]c2ccccc21</smiles>

$10_{\text {SO2 }}$<smiles>c1ccc2c(c1)Oc1ccccc1[I+]2</smiles>

10 。<smiles>O=C1c2ccccc2[I-]c2ccccc21</smiles>

$10_{\text {co }}$<smiles>c1ccc2c(c1)Nc1ccccc1[I+]2</smiles>

$10_{\mathrm{NH}}$<smiles>CC(=O)N1c2ccccc2[I+]c2ccccc21</smiles>

$10_{\text {NAC }}$<smiles>c1ccc2c(c1)Cc1ccccc1[I+]2</smiles>

$10_{\mathrm{CH} 2}$<smiles>CC1(C)c2ccccc2[I+]c2ccccc21</smiles>

$10_{C(M e) 2}$

Figure 9. lodininium cations considered in this work.

The reductive elimination barriers of iodininium bromide adducts are plotted against the Lewis acidity of the iodininium cation in Figure 10. Surprisingly, most iodininium cations are less Lewis acidic than the iodolium cation, even when the bridging group is electron-withdrawing, such as a carbonyl or difluoroalkenyl group. Only the derivatives bearing a sulfoxide or a sulfone group provided higher Lewis acidities, with an oxygen being on par with the iodolium cation. Furthermore, most of the iodininium adducts are associated with lower barriers to reductive elimination. This is likely due to the different geometry of the transition states (see Figure 11). 
Indeed, the reductive elimination of iodolium salts is hindered by the important geometrical distortion it implies: the nucleophile must be perpendicular to the plane of the iodolium moiety, and thus benefits from very little stabilization by halogen bonding. In iodininium cations, the linker induces an angle between the two aromatic groups (Figure 11b). The distortion from the adduct to the transition state is thus less important. We can compare this with diphenyliodonium salts (Figure 11c), which readily undergo reductive elimination. In this third case, the nucleophile remains fairly close to the Lewis acidic site of the iodine atom.

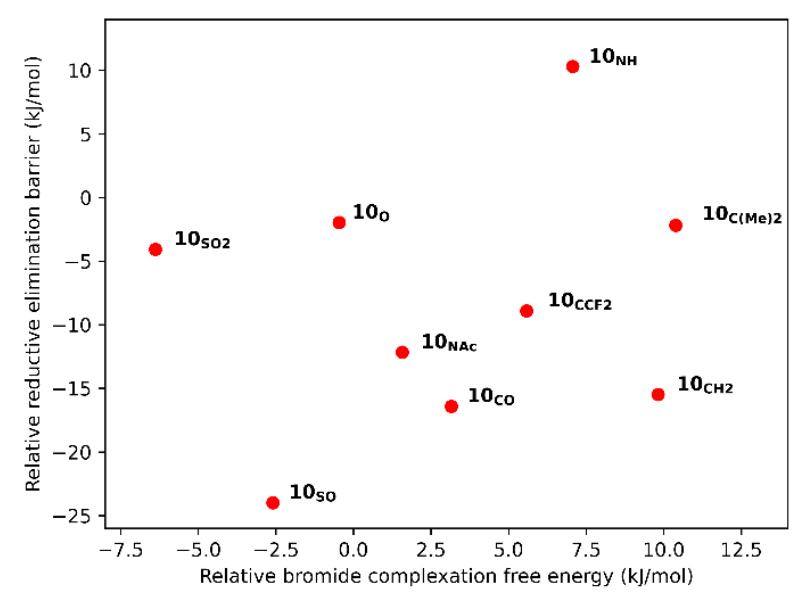

Figure 10. Relative reductive elimination barrier and bromide complexation free energy of iodininium cations 10 compared to the unfunctionalized iodolium cation $\mathbf{1}_{\mathbf{H}}$.

a)

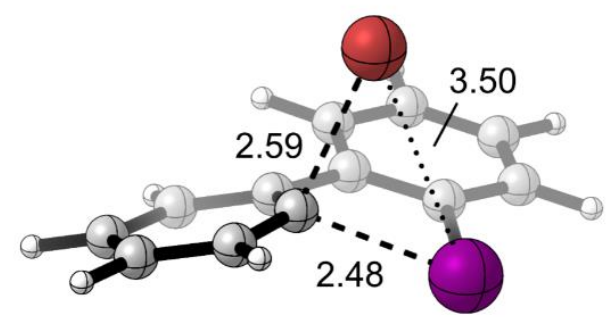

b) $\Delta G \neq=123 \mathrm{~kJ} / \mathrm{mol}$

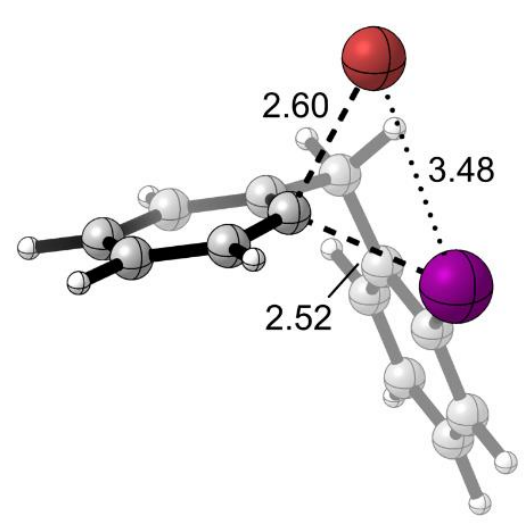

C) $\Delta G \ddagger=112 \mathrm{~kJ} / \mathrm{mol}$

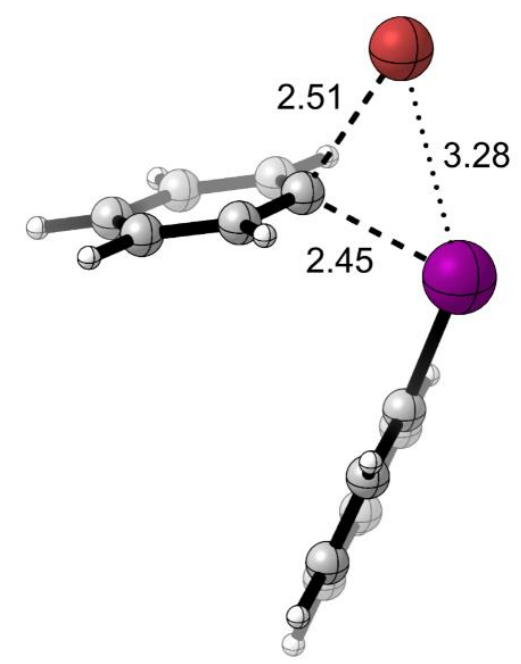

Figure 11. Reductive elimination transition states of: a) iodolium bromide; b) iodininium (methylene bridged) bromide; c) diphenyliodonium bromide.

However, we note that the electron affinities of iodininium cations are systematically less favorable than those of iodolium cations with an equivalent Lewis acidity (Figure 12). This offers a way to escape the nearly direct correlation between Lewis acidity and electron affinity; for example, iodininium $\mathbf{1 1}^{6}$ possesses the exact 
same electron affinity as iodolium $\mathbf{1}_{\mathbf{H}}$ while being notably more Lewis acidic (Figure 13 ). Interestingly, this iodininium is even more Lewis acidic than the analogous iodolium $\mathbf{7}_{\mathrm{F}}$. It thus seems that the bridging group can both reduce the electron affinity and increase the Lewis acidity, while keeping a comparable barrier to reductive elimination.

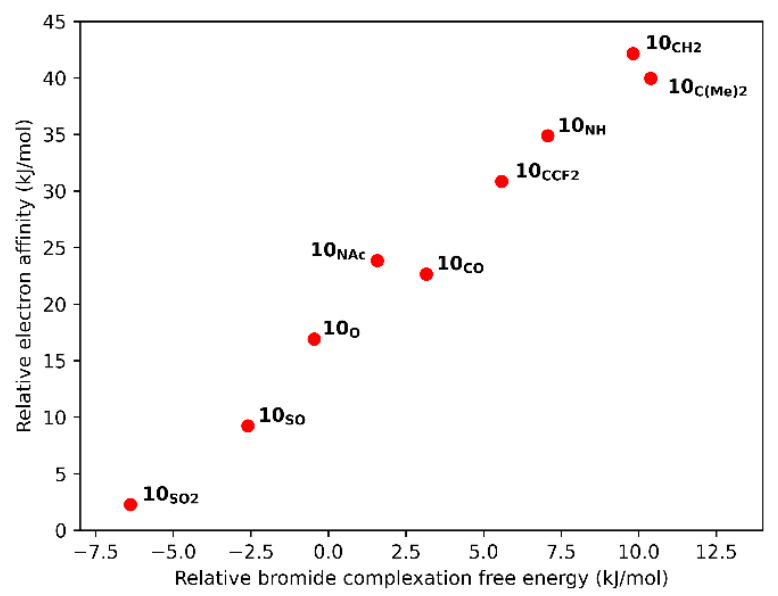

Figure 12. Relative vertical electron affinity and bromide complexation free energy of iodininium cations compared to the unfunctionalized iodolium cation $\mathbf{1}_{\mathbf{H}}$.

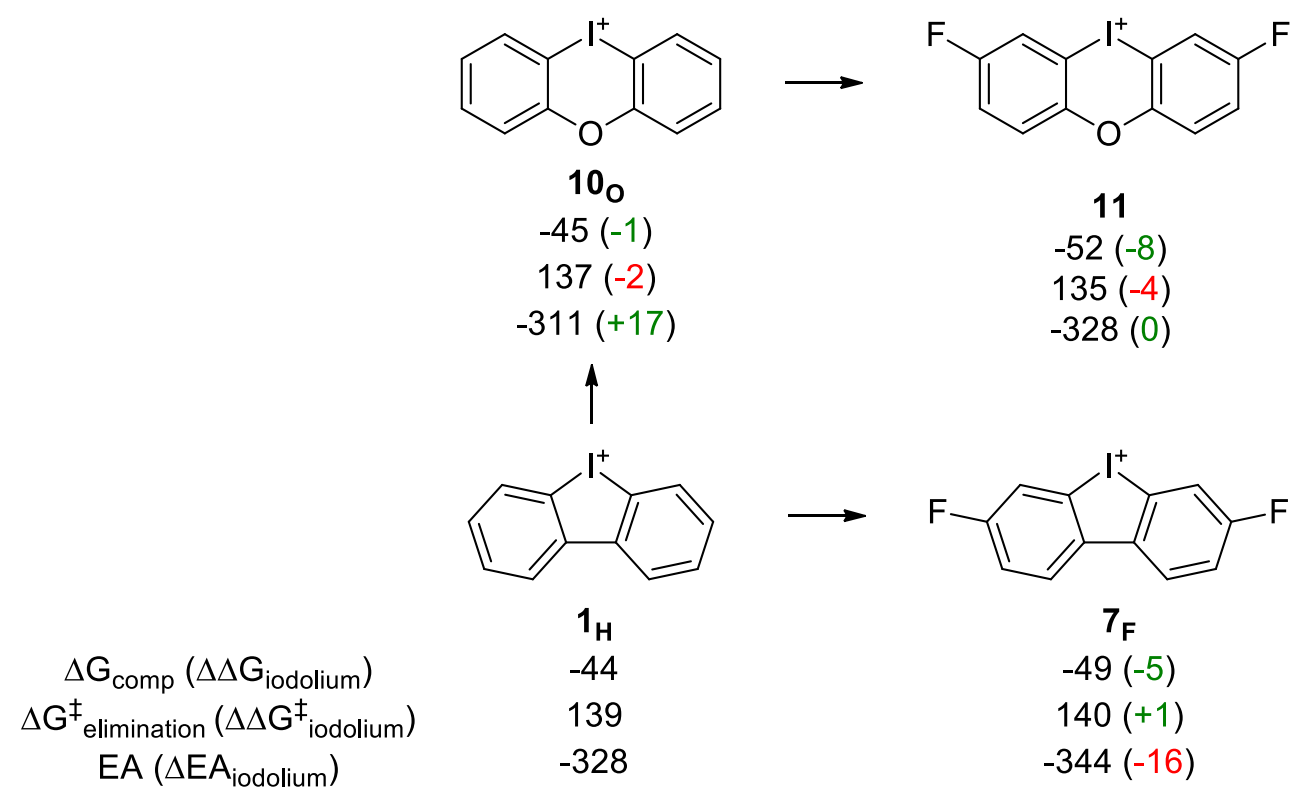

Figure 13. Comparison of fluorinated iodolium and iodininium cations (values in $\mathrm{kJ} / \mathrm{mol}$ ).

Longer bridging alkane groups have also been reported in the literature, and these could be promising future candidates for catalyst design. We thus compared cyclic iodine(III) compounds with different bridging groups, going from no bridging group $\left(\mathbf{1}_{\mathrm{H}}\right)$ to a bridging propylene unit $\left(\mathbf{1 0}_{\mathbf{C H} 2}, \mathbf{1 0}_{(\mathbf{C H} 2) \mathbf{2}} \mathbf{1 0}_{(\mathbf{C H} 2) 3}\right)$ in Figure $14 .{ }^{13,14}$ Unsurprisingly, the barrier to reductive elimination rapidly decreases with the number of methylene units, as the more flexible geometry reduces the distortion required for the reductive elimination. The Lewis acidity and electron affinity are also decreased by adding bridging methylene units. This might partially be explained by the 
weakly electron-donating nature of the methylene units, although this effect is also probably caused by the different geometry. As mentioned before, the acyclic diphenyliodonium cation is significantly less Lewis acidic than its cyclic analog, iodolium $\mathbf{1}_{\mathbf{H}}$. The bridged compound $\mathbf{1 0}_{\mathrm{CH} \mathbf{2}, \mathbf{1 0}} \mathbf{1}_{(\mathbf{C H} 2) \mathbf{2}}$ and $\mathbf{1 0} \mathbf{0}_{(\mathbf{C H} 2) \mathbf{3}}$ bridge the two in terms of geometrical constraint. According to our calculations, the bromide complexation free energy of the diphenyliodonium cation is $-33 \mathrm{~kJ} / \mathrm{mol}$, compared with $-44 \mathrm{~kJ} / \mathrm{mol}$ for iodolium $\mathbf{1}_{\mathrm{H}}$. This fits with the bromide complexation free energy of $\mathbf{1 0}_{(\mathbf{C H} 2) 3}$ : its increase of $14 \mathrm{~kJ} / \mathrm{mol}$ relative to $\mathbf{1}_{\mathrm{H}}$ is composed mostly of the different geometry $(11 \mathrm{~kJ} / \mathrm{mol})$, but also of the inductive effect of the bridging alkane chain $(3 \mathrm{~kJ} / \mathrm{mol})$. Overall,

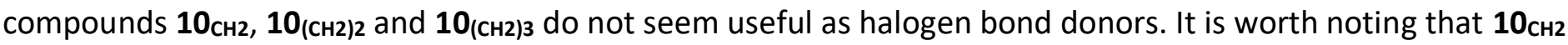
was synthesized as triflate salt and tested by one of our groups. ${ }^{6}$

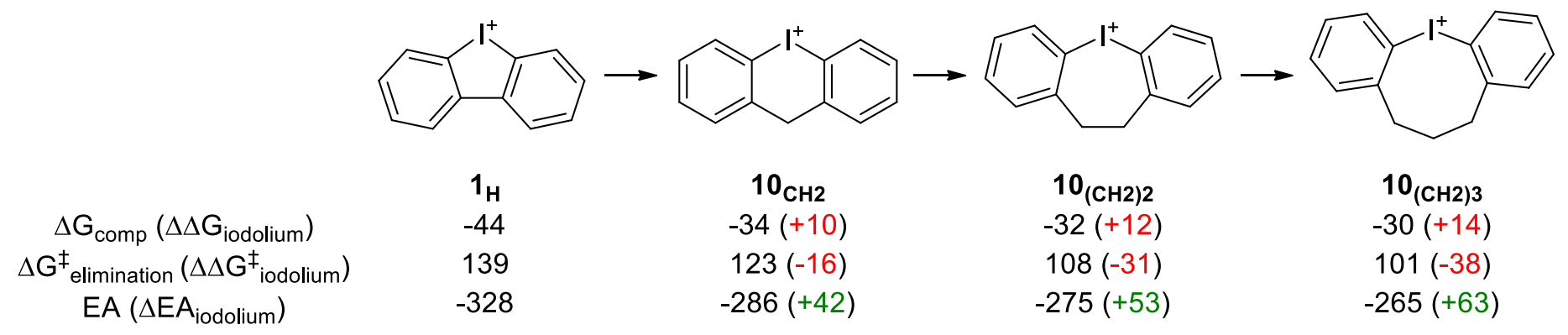

Figure 14. Comparison of cyclic diaryliodonium compounds bridged by an alkane chain of different lengths (values in $\mathrm{kJ} / \mathrm{mol}$ ).

\section{Conclusions}

We have computationally investigated substituted iodolium and iodininium cations for their potential use as halogen bond donors. For each compound, we computed three properties of interest, namely the bromide complexation free energy, the bromide adduct barrier to reductive elimination and the vertical electron affinity of the cation. Except for some specific substitution motifs, the barrier of reductive elimination remains roughly constant for iodolium cations and is decreased in the case of iodininium cations. This indicates that this particular pathway should not result in kinetic instability for iodolium cations. The Lewis acidity was found to be strongly correlated with the vertical electron affinity. Functional groups near the iodine atom were shown to influence this correlation to some extent. It is important to note that iodininium cations are significantly less prone to reduction by SET than iodolium cations with equivalent Lewis acidities. While iodininium cations have only briefly been explored thus far, they constitute a promising new class of iodine(III)-based halogen bond donors. The synthesis and isolation of highly Lewis acidic iodininium salts remains a sizable challenge to be tackled in future works.

\section{Experimental Section}

Computational Method. The calculations were performed using the Gaussian 16 software package. ${ }^{15}$ The calculations were performed with the M062X density functional, in combination with the Def2TZVP basis set for all atoms except iodine, for which Def2TZVPD and corresponding ECP were used. The calculations were performed using SMD implicit solvation model for acetonitrile. The recently corrected radius for iodine atom for 
SMD calculations was used. ${ }^{16}$ Harmonic vibrational frequencies were computed for all optimized structures to verify that they were either minima or transition states, possessing zero or one imaginary frequency, respectively. All the free energies (SMD18 $\left(\mathrm{CH}_{3} \mathrm{CN}\right) / \mathrm{M062X} /[$ Def2TZVP + Def2TZVPD(I)]) are reported in $\mathrm{kJ} / \mathrm{mol}$, incorporate unscaled thermodynamic corrections based on the vibrational analyses and temperature of 298.15 $\mathrm{K}$. The vibrational entropy correction as described by Grimme had a negligeable effect on all results. ${ }^{17}$ The rotational entropy was corrected using manually determined symmetry numbers as described elsewhere. ${ }^{18}$ Additionally, the free energies at $1 \mathrm{~atm}$ concentration were corrected to a $1 \mathrm{M}$ standard state using a $+7.9 \mathrm{~kJ} / \mathrm{mol}$ correction. The bromide anion was modeled as acetonitrile adduct. The free energy of releasing the acetonitrile into the bulk was corrected for a concentration of $18.77 \mathrm{M}(+7.3 \mathrm{~kJ} / \mathrm{mol})$. The vertical electron affinity was calculated as the difference in ZPE-corrected electronic energy between the neutral radical species and the cation. The figures of 3D structures were generated using CYLview20. ${ }^{19}$

\section{Acknowledgements}

C. Y. L. and R. R. thank the National Science and Engineering Research Council (NSERC) of Canada, the Canada Foundation for Innovation (CFI), the FRQNT Centre in Green Chemistry and Catalysis (CGCC), and the Université de Sherbrooke for support. Computational resources were provided by Calcul Québec and Compute Canada. S. M. H. thanks the Fonds der Chemischen Industrie for a Dozentenstipendium. R. R. is grateful to NSERC for a Canada Graduate Scholarship (CGS M) and to FRQNT for a Graduate Scholarship (B1X/B2X)

\section{Supplementary Material}

The Supplementary Material contains comparison of calculated bromide complexation free energies with experimental values as well as the Cartesian coordinates, and electronic and free energies of all species.

\section{References}

1. Robidas, R.; Reinhard, D. L.; Legault, C. Y.; Huber, S. M. Chem. Rec. 2021, 21, 1-17. https://doi.org/10.1002/tcr.202100119.

2. Labattut, A.; Tremblay, P.-L.; Moutounet, O.; Legault, C. Y. J. Org. Chem. 2017, 82 (22), 11891-11896. https://doi.org/10.1021/acs.joc.7b01616.

3. Mayer, R. J.; Ofial, A. R.; Mayr, H.; Legault, C. Y. J. Am. Chem. Soc. 2020, 142 (11), 5221-5233. https://doi.org/10.1021/jacs.9b12998.

4. Heinen, F.; Engelage, E.; Dreger, A.; Weiss, R.; Huber, S. M. Angew. Chem. Int. Ed. 2018, 57 (14), 38303833.

https://doi.org/10.1002/anie.201713012.

5. Heinen, F.; Engelage, E.; Cramer, C. J.; Huber, S. M. J. Am. Chem. Soc. 2020, 142 (19), 8633-8640. https://doi.org/10.1021/jacs.9b13309.

6. Reinhard, D. L.; Heinen, F.; Stoesser, J.; Engelage, E.; Huber, S. M. Helv. Chim. Acta 2021, 104 (2), e2000221. 
7. Zhang, Y.; Han, J.; Liu, Z.-J. RSC Adv. 2015, 5 (32), 25485-25488. https://doi.org/10.1039/C5RA00209E.

8. Boelke, A.; Kuczmera, T. J.; Caspers, L. D.; Lork, E.; Nachtsheim, B. J. Org. Lett. 2020, 22 (18), 7261-7266. https://doi.org/10.1021/acs.orglett.0c02593.

9. Heinen, F.; Reinhard, D. L.; Engelage, E.; Huber, S. M. Angew. Chem. Int. Ed. 2021, 60 (10), 5069-5073. https://doi.org/10.1002/anie.202013172.

10. Wolf, J.; Huber, F.; Erochok, N.; Heinen, F.; Guérin, V.; Legault, C. Y.; Kirsch, S. F.; Huber, S. M. Angew. Chem. Int. Ed. 2020, 59 (38), 16496-16500. https://doi.org/10.1002/anie.202005214.

11. Yunusova, S. N.; Novikov, A. S.; Soldatova, N. S.; Vovk, M. A.; Bolotin, D. S. RSC Adv. 2021, 11 (8), $4574-$ 4583.

https://doi.org/10.1039/DORA09640G.

12. Rienstra-Kiracofe, J. C.; Tschumper, G. S.; Schaefer, H. F.; Nandi, S.; Ellison, G. B. Chem. Rev. 2002, 102 (1), 231-282.

https://doi.org/10.1021/cr990044u.

13. Tolstaya, T. P.; Sukhomlinova, L. I.; Vanchikov, A. N.; Bumagin, N. A. Chem. Heterocycl. Compd. 1999, 35 (1), 106-111. https://doi.org/10.1007/BF02251673.

14. Vanchikov, A. N.; Bobyleva, M. S.; Komissarova, E. E.; Kulikov, N. S.; Tolstaya, T. P. Chem. Heterocycl. Compd. 1998, 34 (3), 371-377.

https://doi.org/10.1007/BF02290735.

15. Gaussian 16, Revision C.01, Frisch, M. J.; Trucks, G. W.; Schlegel, H. B.; Scuseria, G. E.; Robb, M. A.; Cheeseman, J. R.; Scalmani, G.; Barone, V.; Petersson, G. A.; Nakatsuji, H.; Li, X.; Caricato, M.; Marenich, A. V.; Bloino, J.; Janesko, B. G.; Gomperts, R.; Mennucci, B.; Hratchian, H. P.; Ortiz, J. V.; Izmaylov, A. F.; Sonnenberg, J. L.; Williams-Young, D.; Ding, F.; Lipparini, F.; Egidi, F.; Goings, J.; Peng, B.; Petrone, A.; Henderson, T.; Ranasinghe, D.; Zakrzewski, V. G.; Gao, J.; Rega, N.; Zheng, G.; Liang, W.; Hada, M.; Ehara, M.; Toyota, K.; Fukuda, R.; Hasegawa, J.; Ishida, M.; Nakajima, T.; Honda, Y.; Kitao, O.; Nakai, H.; Vreven, T.; Throssell, K.; Montgomery, J. A., Jr.; Peralta, J. E.; Ogliaro, F.; Bearpark, M. J.; Heyd, J. J.; Brothers, E. N.; Kudin, K. N.; Staroverov, V. N.; Keith, T. A.; Kobayashi, R.; Normand, J.; Raghavachari, K.; Rendell, A. P.; Burant, J. C.; Iyengar, S. S.; Tomasi, J.; Cossi, M.; Millam, J. M.; Klene, M.; Adamo, C.; Cammi, R.; Ochterski, J. W.; Martin, R. L.; Morokuma, K.; Farkas, O.; Foresman, J. B.; Fox, D. J. 2016.

16. Engelage, E.; Schulz, N.; Heinen, F.; Huber, S. M.; Truhlar, D. G.; Cramer, C. J. Chem. - Eur. J. 2018, 24 (60), 15983-15987. https://doi.org/10.1002/chem.201803652.

17. Grimme, S. Chem. - Eur. J. 2012, 18 (32), 9955-9964.

https://doi.org/10.1002/chem.201200497.

18. Gilson, M. K.; Irikura, K. K. J. Phys. Chem. B 2010, 114 (49), 16304-16317.

https://doi.org/10.1021/ip110434s.

19. CYLview20, Legault, C. Y. Université de Sherbrooke, 2020, (https://www.cylview.org). 